\title{
Mineração
}

\section{Remoção de inclusões minerais em zircões}

\author{
Sydney Sabedot \\ Professor Doutor do UNILASALLE \\ E-mail: sabedot@unilasalle.edu.br \\ Carlos Hoffmann Sampaio \\ Professor Doutor do Departamento de Metalurgia da UFRGS \\ E-mail:sampaio@ufrgs.br
}

\section{Resumo}

A mina do Guaju, no Estado da Paraíba, produz variados tipos de concentrado de zircão, como subprodutos do beneficiamento de dunas litorâneas. O Concentrado de Zirconita B é um dos tipos e é considerado de baixa qualidade, devido a ocorrência de inclusões minerais em cerca de $28 \%$ dos grãos de zircão. Com o objetivo de tornar a matéria-prima um produto de qualidade superior, desenvolveram-se estudos mineralógicos em microssonda analítica e uma rota de beneficiamento mineral, em nível de bancada, que incluiu processos de separação magnética e eletrostática, aquecimento em forno de microondas, moagem e peneiramento. Os resultados indicaram que os principais minerais que compõem as inclusões são pirrotita, biotita, quartzo, ilmenita e apatita. Indicaram também que os processos geraram produtos e subprodutos que incorporaram uma valorização comercial de 77\% em relação à matéria-prima original, com uma perda mássica de $12 \%$. Esses valores indicaram que a rota para a remoção das inclusões minerais teve êxito, mas há desafios operacionais e econômicos a serem considerados pela empresa, caso se decidir implantá-la industrialmente.

Palavras-chave: zircão, tecnologia mineral, processamento mineral.

\begin{abstract}
The Guaju mine, Paraíba State, produces different types of zircon concentrate, as a by-product of coastal dunes treatment. The denominated Concentrate Zirconita B is one of the products. It is considered low quality, due to the occurrence of mineral inclusions in about $28 \%$ of the zircon grains. Mineralogical characterization studies in an electron microprobe were carried out. A schematic of mineral treatment was developed on bench scale, including the processes of magnetic and electrostatic separation, heating in microwave oven, grinding and sizing. The results indicate that the main minerals that take part in the inclusions are pyrrhotite, biotite, quartz, ilmenite and apatite. They also show that the treatment processes generate products and by-products that incorporate a commercial valorization of $77 \%$ in relation to the original raw material, with a $12 \%$ mass loss. The flowsheet studied indicates very good results, but there are operational and economical challenges to be considered by the company, to implant the processes in the industrial operations.
\end{abstract}

Keywords: zircon, mineral technology, mineral processing. 


\section{Introdução}

A demanda global por matérias-primas minerais, na atualidade, exige que a indústria extrativa invista em tecnologias para melhorar a qualidade de seus produtos, permitindo melhor aplicação do insumo na indústria de transformação e conquista de novos mercados. A tecnologia mineral permitiu que o segmento dos minerais industriais crescesse substancialmente nos últimos anos, por apresentarem diversidade de aplicações e preços. Nesse contexto, a mineração tem dado sua contribuição para a sustentabilidade do setor, porque, ao investir em tecnologias, permite uma melhor aplicação dos recursos não-renováveis.

O zircão é um mineral industrial que tem variadas aplicações: cerca de 95\% de todo o zircônio consumido está na forma de zircão, óxido de zircônio, ou outras substâncias químicas de zircônio. O restante é consumido como zircônio metálico e ligas contendo zircônio. O zircão usado para revestimentos em moldes de fundição aumenta a resistência à penetração de metal e dá um acabamento uniforme. Moído ou granulado, é usado em pinturas refratárias. Zircão na forma de tijolos e blocos refratários são usados em fornos. Óxido de zircônio estabilizado exibe alta reflectância e boa estabilidade térmica, sendo usado como um opacificante e pigmento em coberturas coloridas para diversos produtos cerâmicos (Hedrick, 2001).

Garnar (1994) indica que concentrados de zircão devem ter as seguintes especificações: $\mathrm{ZrO}_{2}+\mathrm{HfO}_{2}$ (mínimo 6566\%); $\mathrm{Fe}_{2} \mathrm{O}_{3}$ (máximo 0,02-0,10\%); $\mathrm{TiO}_{2}$ (máximo 0,10-0,35\%); $\mathrm{Al}_{2} \mathrm{O}_{3}$ (máximo 0,2 - 2,0\%). Exceto a primeira, as demais substâncias são contaminantes.

No Brasil, apenas duas empresas produzem concentrados de zircão:
Millennium Inorganic Chemicals do Brasil S/A (MIC), que opera a mina do Guaju e é a maior produtora; Indústrias Nucleares do Brasil S/A, que opera no Estado do Rio de Janeiro (DNPM, 2004).

A MIC produz concentrados de zircão como subprodutos do beneficiamento de dunas litorâneas inconsolidadas, mineralizadas com cerca de $3,7 \%$ de minerais pesados. Cerca de $28 \%$ dos zircões da jazida contêm inclusões minerais de dimensões e composições variadas, que contaminam as matérias-primas (Sabedot \& Sampaio, 2002), as quais são qualificadas conforme os teores dos óxidos anteriormente referidos. Com o objetivo de se agregar valor comercial a um concentrado de zircão considerado de baixa qualidade, realizaram-se estudos para identificar a mineralogia das inclusões e para removê-las com processos de beneficiamento mineral. Esse artigo trata da metodologia e dos principais resultados dos estudos e dos fatores operacionais e econômicos relacionados aos resultados.

\section{Material e métodos}

O estudo das inclusões minerais teve início com a seleção manual de 300 grãos de zircão do Concentrado Zirconita B (CZB), com o auxílio de uma lupa binocular, na qual, com o aumento de 80 vezes, as inclusões estavam visíveis. Os grãos selecionados foram colados em uma lâmina de vidro. Desgastados por lixas, expuseram 68 inclusões que foram analisadas em microscópio óptico e em microssonda analítica. Parte das inclusões foi fotografada.

A remoção das inclusões ocorreu em equipamentos de laboratório, nas seguintes operações: separação eletrostática, separação magnética, aquecimento em forno de microondas e moagem. A amostra processada foi a mesma do estudo mineralógico das inclusões. A Figura 1 mostra o fluxograma das operações.

Inicialmente, a amostra do CZB passou no separador eletrostático da marca Krupp, tipo Corona, para a remoção do rutilo liberado que contamina o CZB. Os parâmetros de operação foram: tensão elétrica (30 kV) e rotação do rolo (100 rpm).

A fração não-condutora da separação eletrostática, de interesse para a continuidade do estudo, passou no separador magnético de rolo induzido, da marca Carpco, modelo MIH-13.111-5, para a remoção dos minerais magnéticos liberados, principalmente ilmenita, que também contaminam o CZB. Os parâmetros foram: máxima intensidade de campo magnético permitida no equipamento e velocidade do rolo em 33 rpm.

A fração não-magnética, de interesse na continuidade do estudo, foi aquecida em forno de microondas de laboratório, em bateladas com massa de 600 gramas, operado com potência de $500 \mathrm{~W}$ e tempo de aquecimento de 7 minutos. $\mathrm{O}$ aquecimento em microondas foi considerado devido às discussões de Haque (1999) e Kingman e Rowson (1998), nas revisões sobre a energia das microondas nos processos de tratamento mineral. Segundo os pesquisadores, o aquecimento dos minerais varia conforme suas composições químicas e propriedades físicas. Em geral, minerais metálicos, como a pirita, atingem altas temperaturas $\left(>1000^{\circ} \mathrm{C}\right)$ sob a ação das microondas, no tempo de 7 minutos. Os nãometálicos e transparentes, como o quartzo, atingem temperaturas em torno de $80^{\circ} \mathrm{C}$, no mesmo tempo. Ainda segundo os pesquisadores, o aquecimento rápido com microondas é importante na liberação de minerais econômicos associa-

Figura 1 - Operações para a remoção de inclusões minerais do CZB.

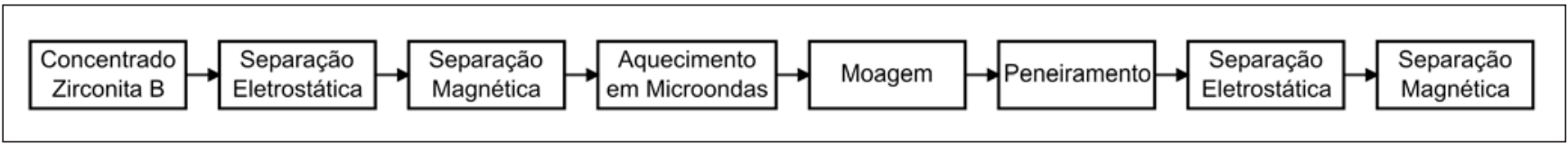


Sydney Sabedot et al.

dos a uma ganga mineral. Devido à diferença entre os coeficientes de dilatação dos minerais, as microondas atuam de forma a provocar fraturamentos nas zonas de contato entre os diferentes minerais, facilitando, numa etapa posterior de britagem/moagem, a separação entre eles. Por este motivo, submeteu-se o CZB ao aquecimento em microondas, considerando que o zircão estudado é transparente.

A moagem serviu para provocar a quebra dos zircões portadores de inclusões, previamente fraturados com a ação das microondas e, desta forma, liberar ou expor as inclusões. Utilizou-se um moinho de impacto com alimentação e saída contínuas, para evitar a cominuição demasiada do material.

Peneirado, o produto da moagem originou três frações: $+0,063 \mathrm{~mm},-0,063$ $+0,020 \mathrm{~mm}$ e $-0,020 \mathrm{~mm}$. A primeira fração foi considerada a mínima granulometria para a continuidade dos estudos; a segunda fração será utilizada para estudos futuros com flotação; a terceira fração foi passada no separador magnético cryofilter, de laboratório, com campo magnético de $5 \mathrm{~T}$, para se avaliar o provável aproveitamento do material fino e portador das inclusões removidas dos zircões.

A fração $+0,063 \mathrm{~mm}$ foi passada no separador eletrostático Corona; o produto não-condutor foi passado no separador magnético Carpco. Essas operações permitiriam a remoção das inclusões condutoras e magnéticas, liberadas ou expostas, nos zircões quebrados pela moagem. Os parâmetros operacionais foram os mesmos anteriormente citados para os equipamentos.

\section{Resultados}

\subsection{Estudos mineralógicos}

O estudo mostrou diversidade mineralógica das inclusões. A Tabela 1 mostra as inclusões identificadas nos 68 grãos de zircão analisados. As Figuras 2 e 3 mostram grãos de zircão com as inclusões identificadas.

Tabela 1 - Inclusões minerais identificadas nos grãos de zircão.

\begin{tabular}{c|c|c}
\hline Inclusões Minerais & Quantidade & \% Grãos \\
\hline Pirrotita & 14 & 21 \\
\hline Biotita & 13 & 19 \\
\hline Quartzo & 10 & 15 \\
\hline Ilmenita & 7 & 10 \\
\hline Apatita & 6 & 9 \\
\hline Óxido Te - Ti & 4 & 6 \\
\hline Feldspatos & 4 & 6 \\
\hline Plagioclásios & 3 & 4 \\
\hline Titanita & 2 & 3 \\
\hline Limonita & 2 & 3 \\
\hline Minerais de Cobre & 2 & 3 \\
\hline Anfibólio & 1 & 1 \\
\hline Soma & $\mathbf{6 8}$ & $\mathbf{1 0 0}$ \\
\hline
\end{tabular}
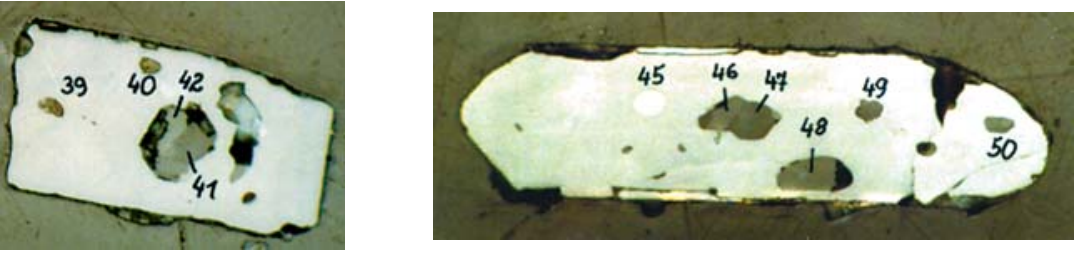

Figuras 2 e 3 - Grãos de zircão com inclusões minerais. Almandina (39 e 40); quartzo (41 e 46); anfibólio (42); pirrotita (45); apatita (47 e 48); feldspato alcalino (49 e 50).

\subsection{Estudos de beneficiamento mineral}

A Tabela 2 indica as recuperações e as análises químicas dos produtos obtidos nos processos de beneficiamento no CZB.

A Figura 4 ilustra grãos de zircão quebrados com inclusões expostas, retirados do produto magnético, pós-peneiramento.

A amostra $-0,020 \mathrm{~mm}$ passada no cryofilter gerou $45,8 \%$ de produto nãomagnético e $54,2 \%$ de produto magnético (ou rejeito). A Tabela 3 mostra os resultados das análises químicas nos produtos.

\section{Discussão dos resultados}

\subsection{Estudos mineralógicos}

Os estudos mineralógicos (Tabela 1) e analíticos das inclusões minerais (Figuras 2 e 3) indicaram que pirrotita, biotita, quartzo, ilmenita e apatita são as principais inclusões nos grãos de zircão do CZB. Esses minerais são parte efetiva das substâncias contaminantes do concentrado.

\subsection{Estudos de beneficiamento mineral}

Na Tabela 2, as linhas destacadas em negrito nas colunas Produto e Massa Relativa indicam os produtos e 
Tabela 2 - Resultados do beneficiamento no CZB

\begin{tabular}{|c|c|c|c|c|c|c|c|c|}
\hline \multirow{3}{*}{ Processo } & \multirow{2}{*}{ Produto } & \multicolumn{2}{|c|}{ Massa (\%) } & \multicolumn{5}{|c|}{ Análise Química (\%) } \\
\hline & & Absoluta & Relativa & $\mathrm{TiO}_{2}$ & $\mathrm{Fe}_{2} \mathrm{O}_{3}$ & $\mathrm{P}_{2} \mathrm{O}_{5}$ & $\mathrm{Al}_{2} \mathrm{O}_{3}$ & $\mathrm{ZrO}_{2}$ \\
\hline & CZB & 100 & 100 & 0,54 & 0,28 & 0,14 & 2,22 & 63,32 \\
\hline \multirow{2}{*}{$\begin{array}{c}\text { Separação } \\
\text { Eletrostática }\end{array}$} & Condutor & 6,0 & 6,0 & - & - & - & - & - \\
\hline & Não-condutor & 94 & 94 & 0,38 & 0,23 & 0,13 & 1,54 & 65,01 \\
\hline \multirow{2}{*}{$\begin{array}{l}\text { Separação } \\
\text { Magnética }\end{array}$} & Magnético & 13,1 & 12,3 & 0,51 & 0,29 & 0,22 & 1,53 & 63,98 \\
\hline & Não-magnético & 86,9 & 81,7 & 0,26 & 0,19 & 0,11 & 1,55 & 64,94 \\
\hline \multirow{3}{*}{ Peneiramento } & $+0,063 \mathrm{~mm}$ & 85,2 & 69,6 & 0,2 & 0,17 & 0,08 & 1,32 & 64,56 \\
\hline & $-0,063+0,020 \mathrm{~mm}$ & 12,5 & 10,2 & 0,12 & 0,24 & 0,13 & 1,01 & 64,56 \\
\hline & $-0,020 \mathrm{~mm}$ & 2,3 & 1,9 & 0,19 & 2,62 & 0,25 & 1,62 & 62,68 \\
\hline \multirow{2}{*}{$\begin{array}{c}\text { Separação } \\
\text { Eletrostática }\end{array}$} & Condutor & 5,9 & 4,1 & - & - & - & - & - \\
\hline & Não-condutor & 94,1 & 65,5 & 0,16 & 0,17 & 0,08 & 1,16 & 65,29 \\
\hline \multirow{3}{*}{$\begin{array}{l}\text { Separação } \\
\text { Magnética }\end{array}$} & Magnético & 30,7 & 20,1 & 0,22 & 0,21 & 0,1 & 1,32 & 65,15 \\
\hline & Mistos & 4,3 & 2,8 & 0,64 & 0,45 & 0,19 & 2,6 & 63,0 \\
\hline & Não-magnético & 65,0 & 42,6 & 0,1 & 0,15 & 0,06 & 0,97 & 65,94 \\
\hline
\end{tabular}

Tabela 3 - Análises químicas (\%) da amostra -0,020 mm.

\begin{tabular}{c|c|c|c|c|c|c}
\hline Produto & $\mathrm{TiO}_{2}$ & $\mathrm{Fe}_{2} \mathbf{O}_{3}$ & $\mathbf{P}_{2} \mathbf{O}_{5}$ & $\mathbf{A l}_{2} \mathbf{O}_{3}$ & $\mathbf{S i O}_{2}$ & $\mathbf{Z r O}_{2}$ \\
\hline Não-magnético & 0,4 & 0,17 & 0,06 & 1,35 & 33,01 & 65,14 \\
\hline Magnético & 1,24 & 0,71 & 0,17 & 3,25 & 32,85 & 62,04 \\
\hline
\end{tabular}

massas finais que efetivamente restaram dos processos aplicados no CZB.

Os produtos condutores da separação eletrostática pré e pós-peneiramento, respectivamente $6 \%$ e $4,1 \%$ da massa relativa, contêm quantidades significativas de rutilo liberado, tendo sido, por isso, considerados rejeitos.

O separador magnético Carpco gerou um produto magnético pré-peneiramento cuja massa relativa $(12,3 \%)$ foi considerada demasiada, por conter cerca de $97 \%$ de zircão. O produto não-magnético do processo ainda continha grãos de ilmenita. Por estes fatos, deduziu-se que não houve eficácia na operação e que o separador Carpco pode ter sido inadequado para o CZB, considerando suas características granulométricas e mineralógicas. As mesmas observações servem para o produto magnético póspeneiramento, com o agravante da redução do $\mathrm{D}_{50}$ devido à moagem, justificando a massa relativa mais alta (20,1\%). Devido às características químicas, esses materiais foram considerados subprodutos dos processos.

A moagem do produto não-magnético pré-peneiramento foi considerada satisfatória por gerar pouca massa de finos (12,1\%). Como o objetivo era fragmentar os grãos de zircão com inclusões, para a liberação ou a exposição destas, tornava-se importante a geração mínima de massa fina, devido à limitação de granulometria para processamento nos separadores eletrostático e magnético. $\mathrm{O}$ material -0,063+0,020 mm foi considerado subproduto do processo.

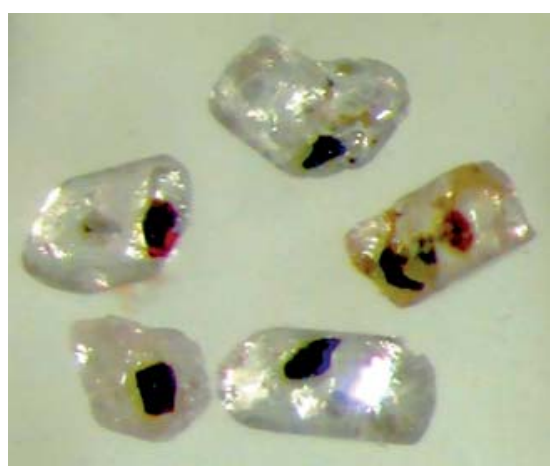

Figura 4 - Grãos de zircão quebrados por moagem, com inclusões minerais expostas.

Não se encontrou uma forma adequada para se avaliar a eficácia do aquecimento no forno de microondas como auxiliar na moagem. Em lupa binocular não se observaram, após o aquecimento, evidências de fratura nas zonas de contato das inclusões com a massa zirconítica que as envolve. O que se observou no produto não-magnético moído foi a ocorrência de muitos grãos quebrados, a maioria sem inclusões, e alguns com inclusões aderidas e expostas, como os mostrados na Figura 4. Em geral, a massa moída apresentou poucos zircões com grandes inclusões, porém houve 
muitos grãos com pequenas inclusões que continuaram incorporadas ao mineral. Essas características evidenciaram que o aquecimento em microondas pode ter sido importante para a liberação das grandes inclusões, mas nem tanto para as pequenas. Os elevados teores das substâncias contaminantes no produto -0,020 mm do peneiramento também podem ser indicativos da eficácia nos processos aquecimento/moagem, considerando que as inclusões minerais liberadas concentraram nesse produto. Por isso, o mesmo foi considerado rejeito.

O produto não-magnético pós-peneiramento corresponde ao Produto Final. Em termos de massa relativa, o valor 42,6\% é considerado baixo. Conforme comentário anterior, as massas excessivas dos produtos magnéticos contribuíram, decisivamente, para o baixo rendimento do Produto Final. O material composto pelos grãos mistos da separação magnética pós-peneiramento foi considerado subproduto nesse estudo.

As inclusões expostas e aderidas em grãos retirados do produto magnético pós-peneiramento (Figura 4) indicaram que a remoção das inclusões foi parcial nas operações aquecimento/moagem. Isto pode ser positivo, na medida em que, aderida ao grão, a inclusão deve ser removida nos processos eletrostático e magnético com mais eficácia do que liberada, considerando os limites granu- lométricos aceitáveis na operação dos equipamentos.

Na Tabela 4, estão indicados os concentrados de zircão comercializados pela MIC e a qualidade atribuída aos mesmos, decorrente de suas análises químicas-padrão (em \%). A qualidade 6 é a mais alta, indicando a matéria-prima de maior valor comercial. Foram introduzidos os concentrados CZB Inicial e CZB Final, assinalados em negrito, para indicar a qualidade atribuída, respectivamente, à matéria-prima original estudada (antes dos processos) e ao Produto Final (depois dos processos).

O Produto Final apresentou resultados que o qualificariam como um concentrado de qualidade intermediária entre os concentrados Zirconita E e Zirconita I. Como não atingiu as especificações da Zirconita E, preferiu-se caracterizá-lo como Zirconita I. Assim, os tratamentos submetidos no CZB Inicial permitiram que a matéria-prima fosse acrescida de 3 pontos, incorporando ganhos consideráveis de qualidade e valor comercial. O produto não atingiu a qualidade máxima devido às substâncias contaminantes, cujos teores ficaram levemente superiores aos da Zirconita E; no entanto, a substância $\mathrm{ZrO}_{2}$ atingiu um valor final quase $1 \%$ absoluto acima desse concentrado.

A fração -0,020 mm do peneiramento, submetida ao processo cryofilter de separação magnética, não apresentou rendimento satisfatório, devido à baixa recuperação de massa não-magnética. Apesar de os resultados terem sido próximos aos do CZB final, devido às suas características químicas e granulométricas, a fração foi considerada rejeito.

\section{Ponderações econômicas}

Observando os resultados da Tabela 2 e os indicativos de qualidade da Tabela 4, elaborou-se a Tabela 5, que simula os valores de venda para os subprodutos e o Produto Final dos processos, considerando suas qualidades químicas e valores comerciais vinculados ao do CZB, atribuídos pela MIC.

O produto Magnético pré-peneiramento tem teores muito próximos aos da Zirconita B (Tabela 4), podendo ser comercializado como tal. O produto 0,063+0,020 mm do peneiramento tem teores que o caracterizariam como Zirconita II, devido ao alto teor de $\mathrm{Fe}_{2} \mathrm{O}_{3}$. O produto Magnético pós-peneiramento tem teores que também o caracterizariam como Zirconita II, devido aos altos teores de $\mathrm{Fe}_{2} \mathrm{O}_{3}$ e $\mathrm{Al}_{2} \mathrm{O}_{3}$. O produto Mistos tem teores compatíveis com o produto Zirconita F. E o Produto Final tem teores que o qualificariam como Zirconita I. Os valores de venda desses produtos totalizariam 1,77 unidades monetárias, repre-

Tabela 4 - Qualidade dos concentrados de zircão produzidos na MIC.

\begin{tabular}{c|c|c|c|c|c|c}
\hline Concentrado & Qualidade & $\mathrm{TiO}_{\mathbf{2}}$ & $\mathrm{Fe}_{\mathbf{2}} \mathbf{O}_{\mathbf{3}}$ & $\mathbf{P}_{\mathbf{2}} \mathbf{O}_{\mathbf{5}}$ & $\mathbf{A l}_{\mathbf{2}} \mathbf{O}_{\mathbf{3}}$ & $\mathbf{Z r O}_{\mathbf{2}}$ \\
\hline Zirconita E & 6 & 0,08 & 0,12 & 0,1 & 0,8 & 65 \\
\hline CZB Final & $\mathbf{5}$ & $\mathbf{0 , 1}$ & $\mathbf{0 , 1 5}$ & $\mathbf{0 , 0 6}$ & $\mathbf{0 , 9 7}$ & $\mathbf{6 5 , 9 4}$ \\
\hline Zirconita I & 5 & 0,2 & 0,16 & 0,15 & 1 & 64,5 \\
\hline Zirconita II & 4 & 0,4 & 0,25 & 0,15 & 1,5 & 64 \\
\hline Zirconita III & 3 & 0,25 & 0,2 & 0,15 & 3,5 & 61 \\
\hline Zirconita B & 2 & 0,55 & 0,35 & 0,15 & 1,5 & 63 \\
\hline CZB Inicial & $\mathbf{2}$ & $\mathbf{0 , 5 6}$ & $\mathbf{0 , 3 1}$ & $\mathbf{0 , 1 4}$ & $\mathbf{2 , 4 7}$ & $\mathbf{6 3 , 0 1}$ \\
\hline Zirconita F & 1 & 1,5 & 0,6 & 0,15 & 3,5 & 59,6 \\
\hline
\end{tabular}


Tabela 5 - Valores de venda para os produtos gerados nos processos.

\begin{tabular}{c|c|c|c}
\hline Produto & $\begin{array}{c}\text { Valor comercial } \\
\text { (un. monet./t) }\end{array}$ & $\begin{array}{c}\text { Massa } \\
(\%)\end{array}$ & $\begin{array}{c}\text { Valor de venda } \\
\text { (un. monet.) }\end{array}$ \\
\hline CZB & 1,00 & 100 & 1,00 \\
\hline Magnético pré-peneiramento & 1,00 & 12,3 & 0,12 \\
\hline$-0,063+0,020 \mathrm{~mm}$ & 2,13 & 10,2 & 0,22 \\
\hline Magnético pós-peneiramento & 2,13 & 20,1 & 0,43 \\
\hline Mistos & 0,90 & 2,8 & 0,03 \\
\hline Produto Final & 2,27 & 42,6 & 0,97 \\
\hline \multicolumn{2}{r}{ Soma dos subprodutos e Produto Final } & 88,0 & 1,77 \\
\hline
\end{tabular}

sentando $77 \%$ sobre o valor de venda do CZB. Com exceção do produto Magnético pré-peneiramento, os demais produtos poderiam ter seus valores acrescidos devido à moagem, que agrega valor comercial. Os rejeitos somaram $12 \%$ de massa efetivamente perdida nos processos. Devido à importância que a matériaprima vem tendo no mercado, atualmente, até mesmo essa massa poderia ter alguma aplicação comercial, o que a tornaria vendável.

\section{Conclusões}

As principais inclusões minerais nos zircões concentrados na mina do Guaju são: pirrotita, biotita, quartzo, ilmenita e apatita. As inclusões minerais são uma das causas da baixa qualidade do CZB.

O separador magnético Carpco utilizado nos estudos não foi eficaz na operação. Além de terem sido encontrados grãos de ilmenita no produto não-magnético, as massas de zircão contidas nos produtos magnéticos pré e pós-peneiramento foram consideradas demasiadas, ocasionando perdas significativas no processo.

As operações de aquecimento em forno de microondas e moagem podem ser consideradas de eficácia média. Em geral, foram encontrados poucos zircões com grandes inclusões na alíquota $+0,063 \mathrm{~mm}$, mas encontraram-se muitos grãos com pequenas inclusões que continuaram incorporadas ao mineral.

A matéria-prima usada nos estudos tinha, inicialmente, uma qualidade 2, numa escala de 1 a 6 , na qual o valor 6 representa a qualidade superior entre os concentrados produzidos na MIC. Submetida aos processos, atingiu a qualidade 5, com uma recuperação mássica do Produto Final considerada baixa (42,6\%). No entanto, os subprodutos dos processos têm valor comercial, exceto $12 \%$ da massa inicial, considerada rejeito, devido aos teores elevados de substâncias contaminantes.

O Produto Final e os subprodutos dos processos para a remoção das inclusões minerais do CZB incorporaram uma valorização comercial de 77\% à matéria-prima original, com uma perda mássica de apenas 12\%. Esses fatos permitiram deduzir que houve êxito na escolha da rota de beneficiamento, em nível de bancada. Industrialmente, os desafios serão: obtenção da granulometria fina dos concentrados de zircão; avaliar se a produção projetada de CZB compensaria a implantação da rota; avaliar se as relações investimento para a implantação da rota x custo operacional x benefício são favoráveis.

\section{Agradecimentos}

Os autores agradecem à empresa Millennium Inorganic Chemicals do Bra- sil S/A, pela cessão de amostras e análises químicas; ao Instituto de Mineralogia da Universidade de Aachen, Alemanha, pelas análises mineralógicas e químicas em microssonda; ao Grupo de Processamento Mineral da Universidade de Aachen (AMR) e seu coordenador, Professor Hermann Wotruba, pela disponibilidade dos equipamentos e orientações para os testes de beneficiamento mineral; à CAPES, pela bolsa sanduíche e demais despesas pagas para a realização dos estudos.

\section{Referências bibliográficas}

DNPM. Departamento Nacional da Produção Mineral. Sumário Mineral Brasileiro. Brasília, 2004.

GARNAR, T. E. Industrial Minerals and Rocks. $6^{\mathrm{a}}$ ed. New York: Donald D. Carr Senior Editor. Zirconium and hafnium minerals, p.1159-1165, 1994.

HAQUE, K. E. Microwave energy for mineral treatment processes - a brief review. International Journal of Mineral Processing, n.57, p.1-24, 1999.

HEDRICK, J. B. Zirconium and Hafnium. United States Geological Survey Minerals Yearbook, p.86.1-86.10, 2001.

KINGMAN, S. W., ROWSON, N. A. Microwave treatment of minerals - a review. Minerals Engineering, v.11, n.11, p.1081-1087, 1998.

SABEDOT, S., SAMPAIO, C. H. Caracterização de zircões da Mina Guaju (PB). REM Revista Escola de Minas, v. 55, n.1, p. 4953, 2002.

Artigo recebido em 15/08/2005 e aprovado em 06/04/2006. 